\title{
Features microcirculatory disturbances in the area of double-row enteric anastomosis in immature and mature dogs
}

\begin{abstract}
Experiments were performed on 20 puppies and 15 adult dogs of both sexes. We determined pronounced microcirculation disturbance after the formation of two-row anastomosis on puppies in suture region and surrounding areas of the small intestine. Predominantly transition of liquid portion of the blood from vessels in tissue occurs because of a essential increase in vascular permeability transition, that has been demonstrated by a significant increase in capillary filtrate and plasma protein loss. These rates have increased respectively to 8.86 times
\end{abstract}

Background: Currently, a large number of scientific papers were devoted to the study microcirculation in intestinal anastomosis.1,2 Numerous studies have established sufficient multiform change in violation of local blood flow caused by complex relationships neuro-reflex, hemodynamic, metabolic and biological reactions.3,4 Where in particular interest in this issue is the consideration in foreshortening of the growth and development of the organism.5

Aim: Analysis of the micro circulatory and morphological changes in the area of double-row enteric anastomosis in dogs of various ages.

Materials \& methods: Experiments were performed on 20 puppies and 15 adult dogs of both sexes. Intestinal anastomosis formation carried out by the type of "end-to-end" double-row suture. We investigated the microcirculation in the vessels of the mesentery of the small intestine, determined Tran's capillary exchange through capillary filtrate and the plasma protein loss, blood viscosity, hematocrit, the coefficient deformation erythrocytes, erythrocyte sedimentation rate.

Results: We determined pronounced microcirculation disturbance after the formation of two-row anastomosis on puppies in suture region and surrounding areas of the small intestine. Predominantly transition of liquid portion of the blood from vessels in tissue occurs because of an essential increase in vascular permeability transition that has been demonstrated by a significant increase in capillary filtrate and plasma protein loss. These rates have increased respectively to 8.86times $(\mathrm{P}<0.01)$ and $200 \%$ $(\mathrm{P}<0.05)$. Blood rheology deteriorated as evidenced by the increase in viscosity by $49.2 \% \quad(\mathrm{P}<0.05)$. Erythrocyte sedimentation rate decreased to $66.28 \% \quad(\mathrm{P}<0.01)$ that was probably associated with significant haemo concentration. The coefficient deformation erythrocytes didn't change essential. Vessels mesentery adjacent to the anastomosis zone was investigated biomicroscopic and a significant slowing of blood flow in all the venules and capillaries with the development of some blood stasis was recorded. There were multiple peri vascular hemorrhage. The pronounced void vessels hemo microcirculatory bed was defined. The number of functioning capillaries was $33.28+3.21 \%(\mathrm{P}<0.001)$ (Table 1$)$.
Volume 2 Issue 4 - 2015

\author{
S A Markos'yan \\ Department of Surgery, The Mordovian state university of a \\ name of N.P. Ogarwov, Russia
}

\begin{abstract}
Correspondence: S A Markos'yan, Department of Surgery, The Mordovian state university of a name of N.P. Ogarwov, Russia, Tel +79176990604, Email markosyansa@mail.ru
\end{abstract}

Received: August 3I, 20I5 | Published:September 26, 2015

\section{Introduction}

At morphological examination of changes, occurring in the abdomen, existence of massive adhesive process was detected. In the anastomosis pronounced inflammation was distinguished. On the inner line of stitches we observed ulcerative process most pronounced at the top of the suture tissue fold. It also fixed the areas of necrosis with fibrinous and purulentim positions. Microscopic examination indicated significant edema, hyperemia, dilatation of arterioles, capillaries and venules, necrosis of the intestine wall, captured suture. The most pronounced pathological process was observed in the mucosa and sub mucosa of the intestinal wall. For 7 thday after the operation massive adhesions in the abdominal cavity were defined in all the puppies. The phenomena of inflammation in the anastomosis were moderate.
The comparatively smaller disorder trans capillary exchange in the area of anastomosis and the adjacent areas was registered in adult dogs. Capillary filtrate increased to 6.13times $(\mathrm{P}<0.01)$, protein loss-by $150 \%(\mathrm{P}<0.01)$. Changes in the rheological properties of blood were insignificant (Table 2). The significant slowing of blood flow was observed in all venules and some capillaries of the bowel mesentery. Blood stasis was supervised in many venules; there were isolated areas of peri vascular hemorrhage. The moderate develop mentarteriolo-venular anastomosis was determined. The number of functioning capillaries equaled to $60.71+1.82 \%(\mathrm{P}<0.05)$.

After the laparotomy a small quantity of serous effusion and loose adhesions was discovered in the abdominal cavity. The adhesive process was presented multiple adhesions between the parietal peritoneum, adjacent organs and the outer intestine wall with anastomosis. In 
the area of double-row enteric anastomosis pronounced edema, hyperemia of organ wall with areas of hemorrhages and ulcerations were distinguished. Microscopic we recorded significant tissues congestion, their infiltration of polymorpho nuclear leukocytes and erythrocytes. A large fibrin number and blood cells were defined in the contact zone of the anastomosis organ portions. Massive adhesive process paid attention after opening the abdominal cavity for the $7^{\text {th }}$ day after the operation. Macroscopic phenomena of inflammation in the anastomosis were not observed.

Table I The microcirculatory parameters change in the area of double-row enteric anastomosis in immature animals

\begin{tabular}{lll}
\hline Index & $\begin{array}{l}\text { Input } \\
\text { data, } \\
\mathbf{n}=\mathbf{1 0}\end{array}$ & Test data, $\mathbf{n}=\mathbf{1 0}$ \\
\hline Capillary filtrate, ml & $2.6 \pm 0.4$ & $23.03 \pm 4.13(\mathrm{p}<0.01)$ \\
Plasma protein loss, \% & $0.25 \pm 0.01$ & $0.75 \pm 0.04(\mathrm{p}<0.001)$ \\
Blood viscosity, conv. un. & $2.5 \pm 0.24$ & $3.73 \pm 0.37(\mathrm{p}<0.05)$ \\
Coefficient deformation erythrocytes & $0.54 \pm 0.02$ & $0.53 \pm 0.0(\mathrm{p}>0.05)$ \\
$\begin{array}{l}\text { Erythrocyte sedimentation rate, } \mathrm{mm} / \\
\text { hr }\end{array}$ & $8.6 \pm 0.4$ & $2.9 \pm 0.24(\mathrm{p}<0.001)$ \\
\hline
\end{tabular}

$M+m$, where $M$, arithmetic mean,

$M$, the average error of the arithmetic mean,

$\mathrm{P}$, an indicator of the reliability of differences in relation to test data.

Table 2 The microcirculatory parameters change in the area of double-row enteric anastomosis in mature animals

\begin{tabular}{lll}
\hline Index & Input data, $\mathbf{n}=\mathbf{1 0}$ & Test data, $\mathbf{n}=\mathbf{1 0}$ \\
\hline Capillary filtrate, ml & $2.2 \pm 0.19$ & $13.49 \pm 2.57(\mathrm{p}<0.01)$ \\
Plasma protein loss, \% & $0.2 \pm 0.01$ & $0.5 \pm 0.03(\mathrm{p}<0.001)$ \\
$\begin{array}{l}\text { Blood viscosity, conv. un. } \\
\text { Coefficient deformation }\end{array}$ & $2.93 \pm 0.6$ & $3.23 \pm 0.52(\mathrm{p}>0.05)$ \\
$\begin{array}{l}\text { erythrocytes } \\
\begin{array}{l}\text { Erythrocyte sedimentation } \\
\text { rate, mm } / \mathrm{hr}\end{array}\end{array}$ & $0.58 \pm 0.03$ & $0.55 \pm 0.02(\mathrm{p}>0.05)$ \\
\end{tabular}

$M+m$, where $M$, arithmetic mean,

$M$, the average error of the arithmetic mean,

$\mathrm{P}$, an indicator of the reliability of differences in relation to test data.

\section{Conclusion}

A significant microcirculatory disorder in double-row enteric anastomosis tissues leads to the development of severe ischemia and inflammation in the intestinal anastomosis wall. The larger changes in the system of microcirculation record in immature animals that determined the development of the larger pathophysiological and pathomorphological effects in tissue anastomosis.

\section{Acknowledgements}

None.

\section{Conflict of interest}

The author declares no conflict of interest.

\section{References}

1. Dekker JW, Liefers GJ, de Mol van Otterloo JC, et al. Predicting the risk of anastomotic leakage in left-sided colorectal surgery using a colon leakage score. J Surg Res. 2011;166(1):e27-34.

2. Jabaji Z, Stark R, Dunn JC. Regeneration of enteric ganglia in mechanically lengthened jejunum after restoration into intestinal continuity. $J$ Pediatr Surg. 2013;48(1):118-123.

3. Parks DA, Grøgaard B, Granger DN. Comparison of partial and complete arterial occlusion models for studying intestinal ischemia. Surgery. 1982;92(5):896-901.

4. Segal SS. Cell-to-cell communication coordinates blood flow control. Hypertension. 1994;23(6 Pt 2):1113-1120.

5. Romeo E, Jasonni V, Caldaro T, et al. Strictureplasty and intestinal resection: different options in complicated pediatric-onset Crohn disease. $J$ Pediatr Surg. 2012;47(5):944-948. 